\title{
MEDICAL COMORBIDITIES AND QUALITY OF LIFE IN EUTHYMIC BIPOLAR PATIENTS
}

\author{
A. Hakiri ${ }^{1}$, N. Bram ${ }^{1}$, D. Karoui ${ }^{1}$, W. Homri ${ }^{1}$, I. Ben Romdhane ${ }^{1}$, R. Labbane ${ }^{1}$. \\ ${ }^{1}$ Razi Psychiatric Hospital, Psychiatric department "C", La Manouba, Tunisia.
}

\section{Introduction:}

In the last decades there has been an increase in interest for researching metabolic syndrome (MetS) in psychiatric patients and plenty of evidence about their association. However, investigations on the prevalence of metabolic syndrome in patients with bipolar disorder (BD) are still surprisingly rare especially that risk factors of MetS are rarely controlled, often underestimated and insufficiently treated in BD patients.

Objectives:

To assess the impact of medical comorbidities on physical and mental quality of life (QOL) in a Tunisian sample of 103 remitted Bipolar I patients.

\section{Materials and Methods:}

A cross sectional and descriptive study was conducted among 103 patients with BD subtype I during the euthymic period.

clinical and past medical history were collected using a semistructured questionnaire.

QOL was assessed using the Arabic version of the Short Form-12 (SF-12) quality of life survey. This scale gives 2 scores: physical QOL and mental QOL. the average in the general population is around 50 according to the validation study of this scale in 9 European countries.. The higher the score, the better the QOL.

\section{Results and Conclusions:}

The sample consisted of 63 men and 40 women.

The average age was $41.7 \pm 11$ years. Sixty three patients (61\%) had at least one medical illness associated with BD (figure 1).

The mean physical QOL score $=44.8 \pm 9.61$ [extremes 22-61.4] . The mean mental QOL score $=41.72 \pm 9.67$ [extremes 20.4-62.9].

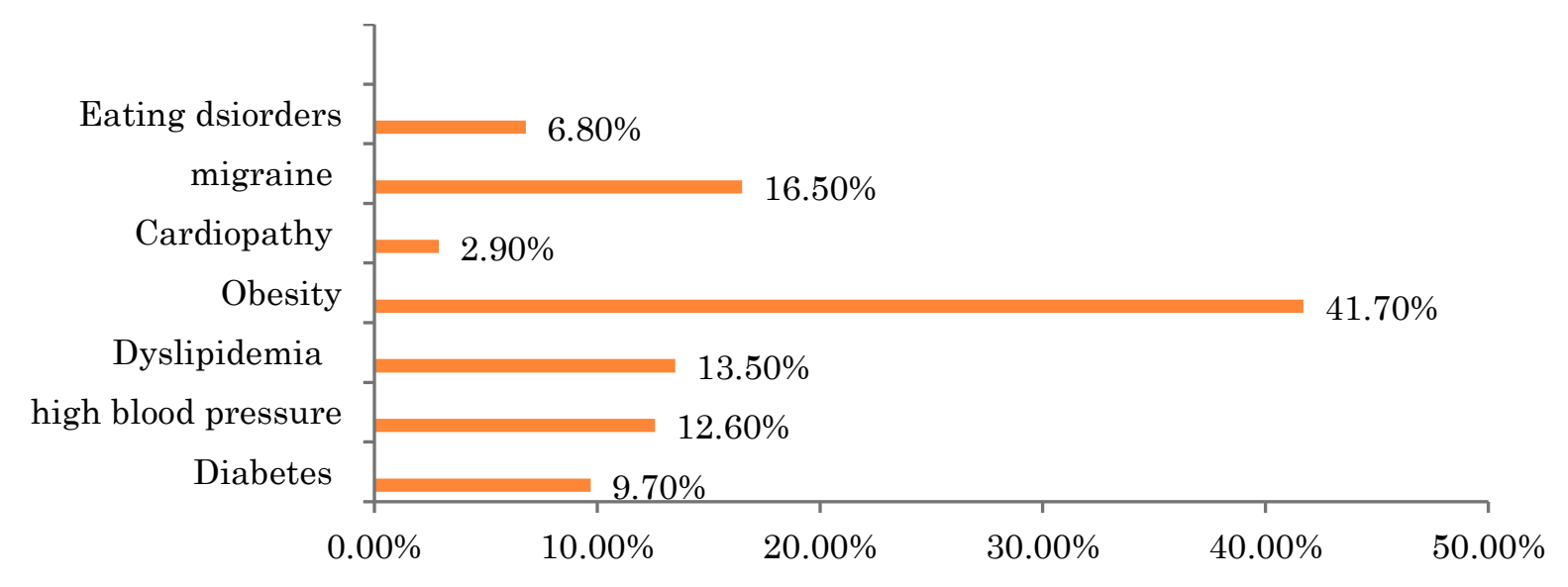

Figure 1 : Frequency of metabolic comorbidities in our sample

1- Bai YM, Li CT, Tsai SJ, Tu PC, Chen MH, Su TP. Metabolic syndrome and adverse clinical outcomes in patients with bipolar disorder. BMC Psychiatry. $2016 ; 16(1): 448$

. 2- Fagiolini A, Chengappa KNR, Soreca I, Chang J. Bipolar Disorder and the Metabolic Syndrome. CNS Dru 2008; 22(8): 655-69

3- Kolotkin RL, Corey-Lisle PK, Crosby RD, Swanson JM, Tuomari AV, L'Italien GJ. Impact of Obesity on Health-related Quality of Life in Schizophrenia and Bipolar Disorder. Obesity. 2008; 16(4): 749-54.
Poor physical QOL was significantly associated with

$(\mathbf{p}=\mathbf{0 . 0 0 1})$, hypertension $(\mathbf{p}=\mathbf{0 . 0 1 5})$, dyslipidemia $(\mathbf{p}=\mathbf{0 . 0 1 1})$.

Poor mental QOL was correlated with hypertension $(\mathbf{p}=\mathbf{0 . 0 4 3})$.

Table I: Correlations between QOL and medical comorbidities

\begin{tabular}{|c|c|c|c|c|c|}
\hline 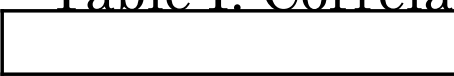 & & Physica & $\mathrm{OOL}$ & Mental & \\
\hline $\begin{array}{l}\text { Personal medical } \\
\text { history }\end{array}$ & $\mathrm{n}$ & Score & $p$ & Score & $p$ \\
\hline Diabetes & & & & & \\
\hline Yes & 10 & $35,759,4$ & 0,001 & $46,367,75$ & 0,11 \\
\hline no & 93 & $45,799,16$ & & $41,299,74$ & 6 \\
\hline High blood pressure & & & & & \\
\hline Yes & 13 & $38,77 \pm 9,41$ & 0,015 & $41,83 \pm 8,26$ & 0,04 \\
\hline no & 90 & $45,68 \pm 9,38$ & & $46,06 \pm 9,66$ & \\
\hline Dyslipidemia & & & & & \\
\hline Yes & 14 & $38,77 \pm 6,9$ & 0,011 & $45,72 \pm 7,59$ & 0,10 \\
\hline No & 89 & $45,76 \pm 9,67$ & & $41,17 \pm 9,83$ & 1 \\
\hline Migraine & & & & & \\
\hline Yes & 17 & $41,5 \pm 11,19$ & 0,121 & $41,58 \pm 8,61$ & 0,92 \\
\hline No & 86 & $45,46 \pm 9,21$ & & $41,82 \pm 9,89$ & 6 \\
\hline Obesity & & & & & \\
\hline Yes & 43 & $44,26 \pm 9,39$ & 0,622 & $43,16 \pm 10,2$ & 0,22 \\
\hline No & 60 & $45,21 \pm 9,84$ & & $40,8 \pm 9,26$ & 4 \\
\hline Eating disorders & & $\mathbf{i}$ & & & \\
\hline Yes & 7 & $45,27 \pm 11$ & 0,897 & $39,3 \pm 11,31$ & 0,49 \\
\hline No & 96 & $44,84 \pm 9,98$ & & $41,96 \pm 9,56$ & \\
\hline
\end{tabular}

\section{Discussion:}

In our study, we found that $61 \%$ of our sample have at least one medical comorbidity to BD. Poor physical and mental QOL were significantly associated with diabetes, high blood pressure and dyslipidemia. Our results are confirmed by previous studies. In fact, The metabolic syndrome has been shown to be comorbid with bipolar disorder in $20-67 \%$ of cases [1]. This association is believed to cause premature mortality in patients with bipolar disorder. It also causes poor adherence to treatment and a deterioration in the quality of life, especially physical QOL[2]. In a study by Kolotkin et al [3] of 1025 patients with bipolar disorder, an impaired quality of life was significantly associated with obesity, which was present in $68 \%$ of participants, and the metabolic complications of obesity. namely diabetes, arterial hypertension and dyslipidemia [2,3]

Conclusions:

Several risk factors, many of them are modifiable, increase the risk of medical comorbidities associated with impaired QOL. This highlights the importance of screening for these conditions at an early stage to employ adequate and early care reducing the risk of cardiovascular disease and premature death 